Jurnal Ilmiah Matematika dan Pendidikan Matematika (JMP)

Vol. 13 No. 2, Desember 2021, hal. 155-166

ISSN (Cetak) : 2085-1456; ISSN (Online) : 2550-0422

\title{
PERAMALAN GARIS KEMISKINAN DI KABUPATEN PURBALINGGA \\ TAHUN 2021-2023 DENGAN METODE DOUBLE EXPONENTIAL SMOOTHING LINIER SATU PARAMETER DARI BROWN
}

\author{
Dwi Anggraeni \\ Jurusan Matematika, FMIPA Universitas Jenderal Soedirman \\ dwi.anggraeni@mhs.unsoed.ac.id \\ Sri Maryani \\ Jurusan Matematika, FMIPA Universitas Jenderal Soedirman \\ sri.maryani.@unsoed.ac.id \\ Suseno Ariadhy \\ Badan Pusat Statistik Kabupaten Purbalingga
}

\begin{abstract}
Poverty is a major problem in a country. The Indonesian government has made various efforts to tackle the problem of poverty. The main problem faced in poverty alleviation is the large number of people living below the poverty line. Therefore, this study aims to predict the poverty line in Purbalingga Regency for the next three periods as one of the efforts that can be made by the government in poverty alleviation. The method used in this study is a one-parameter linear double exponential smoothing from Brown. The software used in this research is Zaitun Time Series and Microsoft Excel. The steps taken are determining the forecasting objectives, plotting time series data, determining the appropriate method, determining the optimum parameter value, calculating the single exponential smoothing value, calculating double exponential smoothing value, calculate the smoothing constant value, calculate the trend coefficient value and perform forecasting. Based on the calculation results, the optimum alpha parameter value is 0.7 with MAPE value of $1.67866 \%$, which means that this forecasting model has a very good performance. The forecast value of the poverty line in Purbalingga Regency for 2021 is Rp. 396,516, in 2022 it is Rp. 417,818, and in 2023 it is Rp. 439,120.
\end{abstract}

Keywords: expoenential smoothing, MAPE, poverty, poverty line.

ABSTRAK. Kemiskinan merupakan permasalahan utama di suatu negara. Pemerintah Indonesia telah melakukan berbagai upaya untuk menanggulangi masalah kemiskinan. Masalah utama yang dihadapi dalam penanggulangan kemiskinan adalah masih besarnya jumlah penduduk yang hidup di bawah garis kemiskinan. Oleh karena itu, penelitian ini bertujuan untuk meramalkan garis kemiskinan di Kabupaten Purbalingga untuk tiga periode yang akan datang sebagai salah satu upaya yang dapat dilakukan oleh pemerintah dalam penanggulangan kemiskinan. Metode yang digunakan dalam penelitian ini adalah double exponential smoothing linier satu parameter dari Brown. Software yang digunakan dalam penelitian ini adalah Zaitun Time Series dan Microsoft Excel. Langkah-langkah yang dilakukan yaitu menentukan tujuan peramalan, melakukan plot time series data, 
menentukan metode yang sesuai, menentukan nilai paramater optimum, menghitung nilai single eponential smoothing, menghitung nilai double exponential smoothing, menghitung nilai konstanta smoothing, menghitung nilai koefisien trend dan melakukan peramalan. Berdasarkan hasil perhitungan, diperoleh nilai parameter optimum alpha sebesar 0,7 dengan nilai MAPE sebesar $1,67866 \%$ yang artinya model peramalan ini memiliki kinerja yang sangat baik. Nilai peramalan garis kemiskinan di Kabupaten Purbalingga untuk tahun 2021 sebesar Rp 396.516, tahun 2022 sebesar Rp 417.818, dan tahun 2023 sebesar Rp 439.120.

Kata Kunci: exponential smoothing, kemiskinan, garis kemiskinan, MAPE.

\section{PENDAHULUAN}

Kemiskinan merupakan permasalahan utama dalam pembangunan ekonomi di negara berkembang seperti Indonesia. Menurut Badan Pusat Statistik, kemiskinan dipandang sebagai ketidakmampuan dari sisi ekonomi untuk memenuhi kebutuhan dasar makanan dan bukan makanan yang diukur dari sisi pengeluaran. Kemiskinan memiliki konsep yang mempengaruhinya yaitu penduduk miskin, garis kemiskinan, persentase penduduk miskin, indeks keparahan kemiskinan, dan indeks kedalaman kemiskinan.

Dalam Sustainable Development Goals (SDGs) yang disepakati oleh para pemimpin dunia, termasuk Indonesia penghapusan kemiskinan merupakan tujuan nomor satu dari 17 tujuan yang berbunyi tidak ada kemiskinan dalam bentuk apapun di seluruh penjuru dunia yang diharapkan dapat dicapai pada tahun 2030. Pemerintah Indonesia telah melalukan berbagai upaya untuk menanggulangi masalah kemsikinan. Menurut BAPPENAS, masalah utama yang dihadapi dalam penanggulangan kemiskinan adalah masih besarnya jumlah penduduk yang hidup di bawah garis kemiskinan. Garis kemiskinan adalah tingkat minimum pendapatan yang dianggap perlu dipenuhi untuk memperoleh standar hidup yang mencukupi di suatu negara. Penduduk yang memiliki rata-rata pengeluaran perkapita per bulan di bawah garis kemiskinan dikategorikan sebagai penduduk miskin.

Indonesia mewajibkan setiap daerah melaporkan masalah kemiskinan, termasuk Kabupaten Purbalingga. Pada tahun 2020 Kabupaten Purbalingga menempati urutan kelima dengan angka kemiskinan tertinggi di Jawa Tengah dan rangking pertama di eks Karasidenan Banyumas. Berdasarkan data BPS, angka 
kemiskinan di Kabupaten Purbalingga yaitu presentase penduduk miskin mengalami kenaikan dari tahun 2019 yaitu 15,03\% menjadi 15,90\% pada tahun 2020 dengan garis kemiskinan dari tahun ke tahun selalu mengalami kenaikan. Kepala BPS Provinsi Jawa Tengah Sentot Bangun Widoyono mengatakan bahwa garis kemiskinan sangat sulit bahkan hampir mustahil bisa diturunkan karena faktor kenaikan/inflasi pasti selalu ada, sedangkan deflasi juga memiliki dampak yang tidak baik. Pemerintah memiliki target ke depan angka kemiskinan di Kabupaten Purbalingga bisa menjadi satu digit.

Sehubungan dengan hal itu, pemerintah perlu melakukan upaya penanggulangan kemiskinan. Salah satu hal yang dapat dilakukan yaitu dengan meramalkan garis kemiskinan untuk masa yang akan datang, karena garis kemiskinan dipergunakan sebagai suatu batas untuk mengelompokkan penduduk menjadi miskin atau tidak miskin dan garis kemiskinan berguna untuk mempertimbangkan pembaharuan sosio-ekonomi, misalnya seperti program peningkatan kesejahteraan dan asuransi pengangguran (Wikipedia, 2008). Untuk meramalkan garis kemiskinan pada masa yang akan datang dapat dilakukan dengan berbagai metode peramalan, salah satunya yaitu exponential smoothing.

Exponential smoothing merupakan suatu tipe teknik peramalan rata-rata bergerak yang melakukan penimbangan terhadap data masa lalu dengan cara eksponensial sehingga data paling akhir mempunyai bobot atau timbangan lebih besar dalam rata-rata bergerak (Handoko, 1984:279). Metode Exponential Smoothing terdiri dari tiga macam, yaitu Single Exponential Smoothing (SES), Double Exponential Smoothing (DES), dan Triple Exponential Smoothing (TES). Masing-masing metode dapat digunakan sesuai dengan pola data yang akan diramalkan. SES baik digunakan untuk data berpola stasioner, sedangkan DES dibagi menjadi dua yaitu double exponential smoothing linier satu parameter dari Brown dan dua parameter dari Holt yang lebih tepat digunakan untuk meramalkan data yang mengalami kecenderungan trend, dan TES digunakan ketika data mempunyai pola data trend dan sifat musiman.

Beberapa penelitian yang menggunakan metode exponential smoothing diantaranya yaitu Fachurrazi (2015) yang meramalkan penjualan obat 
menggunakan metode single exponential smoothing pada toko Obat Bintang Geurugok, Aminudin dan Handoko (2019) yang meramalkan garis kemiskinan dengan metode double exponential smoothing dari Holt, dan Ferima Talia dkk, (2019) yang meramalkan tingkat kemiskinan penduduk Provinsi Kalimantan Timur dengan metode double exponential smoothing.

Berdasarkan hal tersebut, penulis tertarik untuk meramalkan garis kemiskinan di Kabupaten Purbalingga tahun 2021 sampai dengan tahun 2023 menggunakan metode double exponential smoothing linier satu parameter dari Brown. Hasil penelitian ini diharapkan dapat digunakan sebagai salah satu masukan atau bahan pertimbangan bagi pemerintah dalam mengambil keputusan atau menetapkan kebijakan dalam upaya penanggulangan masalah kemiskinan di Kabupaten Purbalingga.

\section{METODE PENELITIAN}

\subsection{Langkah-langkah penelitian}

Peramalan yang baik adalah peramalan yang dilakukan dengan mengikuti langkah-langkah atau prosedur penyusunan yang baik. Berikut adalah langkahlangkah peramalan:

1. Mendefinisikan tujuan peramalan;

2. Membuat dan menganalisis plot time series dari data garis kemiskinan di Kabupaten Purbalingga tahun 2011 sampai dengan tahun 2020;

3. Menentukan metode berdasarkan plot time series data;

4. Menentukan parameter fungsi peramalan terbaik berdasarkan hasil kesalahan peramalan yang minimum;

5. Melakukan peramalan garis kemiskinan di Kabupaten Purbalingga tahun 2021 sampai dengan 2023 menggunakan nilai parameter yang telah ditentukan.

\subsection{Data}

Data yang digunakan dalam penelitian ini adalah data garis kemskinan di Kabupaten Purbalingga tahun 2011 sampai dengan tahun 2020 yang diperoleh 
dari arsip Badan Pusat Statistik Kabupaten Purbalingga. Data yang digunakan adalah sebagai berikut:

Tabel 1. Data Garis Kemiskinan di Kabupaten Purbalingga tahun 2011-2020

\begin{tabular}{|c|c|}
\hline Tahun & $\begin{array}{c}\text { Garis Kemiskinan } \\
\text { (Rupiah) }\end{array}$ \\
\hline 2011 & 230.461 \\
\hline 2012 & 247.508 \\
\hline 2013 & 265.262 \\
\hline 2014 & 275.022 \\
\hline 2015 & 283.366 \\
\hline 2016 & 301.862 \\
\hline 2017 & 313.343 \\
\hline 2018 & 324.735 \\
\hline 2019 & 355.702 \\
\hline 2020 & 375.199 \\
\hline
\end{tabular}

\subsection{Alat dan bahan}

Pada penelitian ini digunakan software Zaitun Time Series untuk menentukan parameter terbaik dan software Microsoft Excel untuk melakukan perhitungan peramalan garis kemiskinan Kabupaten Purbalingga tahun 2021-2023 dengan metode double exponential smoothing dari Brown. Bahan yang dibutukan dalam penelitian ini adalah data, jurnal-jurnal, skripsi, artikel, dan referensi lainnya.

\section{HASIL DAN PEMBAHASAN}

\subsection{Tujuan Peramalan}

Tujuan dari peramalan ini adalah meramalkan garis kemiskinan di Kabupaten Purbalingga tahun 2021 sampai dengan 2023 berdasarkan data garis kemiskinan di Kabupaten Purbalingga tahun 2011 sampai dengan 2020.

\subsection{Plot Time Series}

Sebelum menggunakan metode double exponential smoothing linier satu parameter dari Brown, dilakukan pengamatan terlebih dahulu untuk menentukan cocok atau tidaknya metode yang digunakan. Berikut adalah grafik plot time 
series untuk data garis kemiskinan di Kabupaten Purbalingga tahun 2011 sampai dengan tahun 2020 menggunakan software Microsoft Excel.

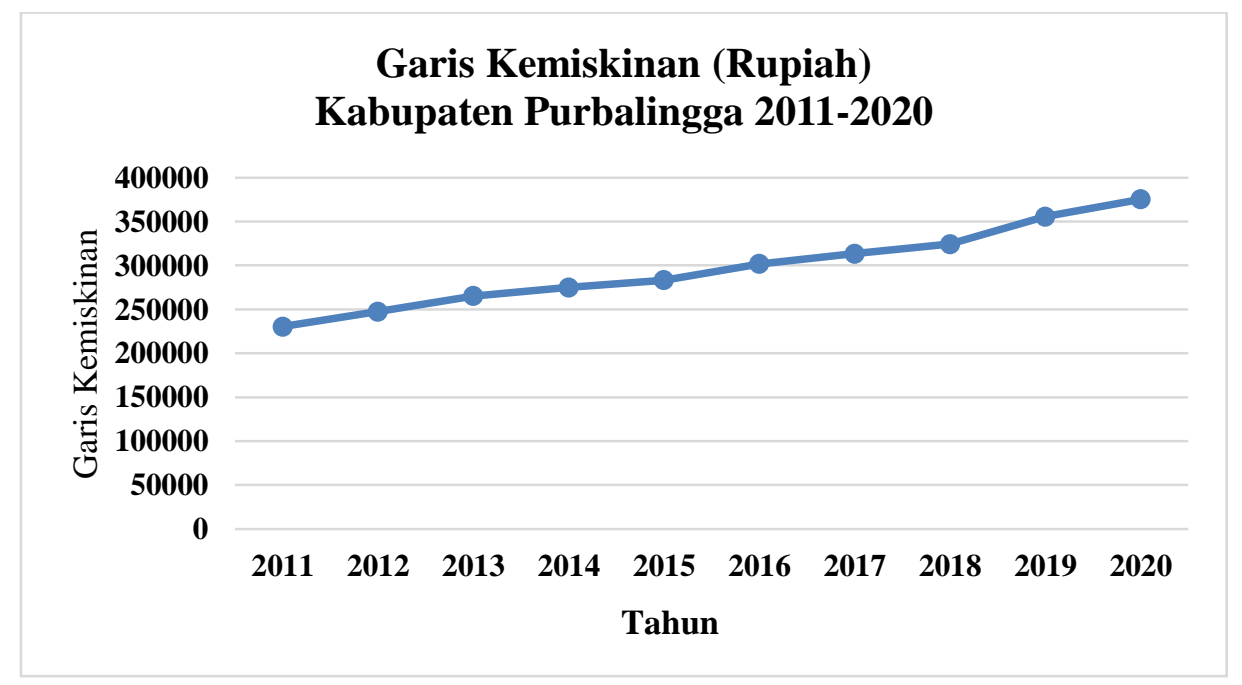

Gambar 1. Plot time series data garis kemiskinan di Kabupaten Purbalingga tahun 2011-2020

Berdasarkan grafik plot time series diatas, garis kemiskinan di Kabupaten Purbalingga tahun 2011 sampai dengan tahun 2020 mengalami kenaikan setiap tahunnya. Kecenderungan data yang naik mengindikasikan bahwa data tersebut memiliki trend. Data juga tidak mempunyai faktor musiman, karena tidak ada data yang naik dan turun pada periode-periode tertentu yang sifatnya berulang. Sehingga, dapat dikatakan bahwa data tersebut mempunyai pola trend, yaitu trend naik. Bentuk visual dari plot data dapat menyatakan suatu kestasioeneran data. Suatu data pengamatan yang mempunyai trend disebut data tidak stasioner (Hanke dan Wichern, 2005:58). Dapat disimpulkan bahwa data mempunyai pola trend dan tidak stasioner. Kelebihan metode double exponential smoothing linier satu parameter dari Brown adalah ketika data menunjukkan tidak stasioner data tidak perlu di transformasi menjadi data stasioner (Inayah, 2010)

\subsection{Menentukan Metode Peramalan}

Berdasarkan plot data time series, metode SES kurang tepat untuk meramalkan garis kemiskinan di Kabupaten Purbalingga, karena metode SES 
lebih tepat digunakan untuk meramalkan data dengan pola horizontal dan stasioner (Makridakis dkk, 1993:10). Selain itu, data tidak menunjukkan adanya sifat musiman. Metode TES digunakan ketika data mempunyai sifat musiman, sehingga metode TES kurang tepat jika digunakan dalam peramalan ini.

Oleh karena itu, dengan adanya data berpola trend dan tidak stasioner, maka metode peramalan yang sesuai untuk meramalkan garis kemiskinan di Kabupaten Purbalingga tahun 2021 sampai dengan 2023 adalah metode DES (Hanke dan Wichern, 2005:58). Metode DES yang akan dipakai dalam peramalan ini adalah metode double exponential smoothing linier satu parameter dari Brown.

\subsection{Menentukan Nilai Parameter}

Peramalan dengan menggunakan metode double exponential smoothing linier satu parameter dari Brown dapat diperoleh dengan menggunakan satu parameter yaitu alpha $(\alpha)$. Interval parameter yang digunakan adalah $0<\alpha<1$ $(\alpha=0,1$ hingga $\alpha=0,9)$ sehingga trial and error dilakukan sebanyak 9 kali. Dalam penelitian ini digunakan Mean Absolute Percentage Error (MAPE) untuk mengetahui ketepatan peramalan. Menurut Makridakis dkk, (1993:39) semakin kecil nilai kesalahan ramalan, maka akan semakin tepat hasil peramalan yang diperoleh. Penentuan parameter dan nilai MAPE yang dihasilkan dihitung dengan bantuan software Zaitun Time Series. Berikut adalah hasil perhitungannya:

Tabel 2. Hasil perhitungan penentuan nilai parameter $\alpha$ dan nilai MAPE dengan software Zaitun Time Series.

\begin{tabular}{|c|c|}
\hline $\boldsymbol{\alpha}$ & MAPE (\%) \\
\hline 0,1 & 1,97749 \\
\hline 0,2 & 2,00411 \\
\hline 0,3 & 1,90391 \\
\hline 0,4 & 1,83916 \\
\hline 0,5 & 1,78736 \\
\hline 0,6 & 1,72931 \\
\hline $\mathbf{0 , 7}$ & $\mathbf{1 , 6 7 8 6 6}$ \\
\hline 0,8 & 1,82801 \\
\hline 0,9 & 1,96293 \\
\hline
\end{tabular}


Menurut Goh dan Law (2002), metode peramalan dikatakan sangat bagus apabila nilai MAPE yang dihasilkan $<10 \%$. Berdasarkan tabel diatas, diperoleh nilai MAPE terkecil yaitu $1,67866 \%(<10 \%)$ dengan alpha 0,7 , ini menunjukkan bahwa hasil peramalan yang dilakukan mempunyai kinerja yang sangat bagus. Sehingga, untuk perhitungan peramalan garis kemiskinan di Kabupaten Purbalingga tahun 2021 sampai dengan tahun 2023 akan menggunakan nilai parameter tersebut.

\subsection{Meramalkan Garis Kemiskinan}

Langkah-langkah menggunakan double exponential smoothing linier satu parameter dari Brown adalah sebagai berikut:

1. menentukan nilai single exponential smoothing

$$
S_{t}^{\prime}=0,7 \cdot \mathrm{X}_{\mathrm{t}}+(1-0,7) S_{t-1}^{\prime} \text {; }
$$

2. menentukan nilai double exponential smoothing

$$
S_{t}^{\prime \prime}=0,7 \cdot S_{t}^{\prime}+(1-0,7) S_{t-1}^{\prime \prime} ;
$$

3. menentukan nilai konstanta smoothing

$$
a_{t}=2 S_{t}^{\prime}-S_{t}^{\prime \prime}
$$

4. menentukan nilai koefisien trend

$$
b_{t}=\frac{0,7}{1-0,7}\left(S_{t}^{\prime}-S_{t}^{\prime \prime}\right)
$$

5. menentukan peramalan untuk periode yang akan datang

$$
\mathrm{F}_{\mathrm{t}+\mathrm{m}}=a_{t}+b_{t} \mathrm{~m}
$$

dengan nilai $a_{t}$ dan $b_{t}$ dapat diambil pada nilai terakhir observasi perhitungan peramalan. Berikut adalah tabel data hasil perhitungan dengan software Microsoft Excel:

Tabel 3. Hasil perhitungan nilai single exponential smoothing, nilai double exponential smoothing, nilai konstanta smoothing, dan nilai koefisien trend dengan menggunakan software Microsoft Excel

\begin{tabular}{|r|c|c|c|c|c|}
\hline Tahun & $\begin{array}{c}\text { Garis } \\
\text { Kemiskinan } \\
\text { (Rupiah) }\end{array}$ & $\boldsymbol{S}_{\boldsymbol{t}}^{\prime}$ & $\boldsymbol{S}_{\boldsymbol{t}}^{\prime \prime}$ & $\boldsymbol{a}_{\boldsymbol{t}}$ & $\boldsymbol{b}_{\boldsymbol{t}}$ \\
\hline 2011 & 230.461 & 230461 & 230461 & 230.461 & \\
\hline
\end{tabular}




\begin{tabular}{|r|r|r|r|r|r|}
\hline 2012 & 247.508 & $242.393,9$ & 238814 & 245.974 & 8353,03 \\
\hline 2013 & 265.262 & 258401,6 & 252525,3 & 264.278 & 13711,28 \\
\hline 2014 & 275.022 & 270035,9 & 264782,7 & 275.289 & 12257,39 \\
\hline 2015 & 283.366 & 279367 & 274991,7 & 283.742 & 10208,98 \\
\hline 2016 & 301.862 & 295113,5 & 289076,9 & 301.150 & 14085,26 \\
\hline 2017 & 313.343 & 307874,1 & 302235 & 313.513 & 13158,04 \\
\hline 2018 & 324.375 & 319424,7 & 314267,8 & 324.582 & 12032,83 \\
\hline 2019 & 355.702 & 344818,8 & 335653,5 & 353.984 & 21385,7 \\
\hline 2020 & 375.199 & 366084,9 & 356955,5 & 375.214 & 21302 \\
\hline
\end{tabular}

Setelah dilakukan perhitungan pada Tabel 2, dapat dihitung nilai peramalan garis kemiskinan di Kabupaten Purbalingga tahun 2021, 2022 dan 2023 dengan menggunakan persamaan:

$$
\mathrm{F}_{\mathrm{t}+\mathrm{m}}=375.124+21302(\mathrm{~m})
$$

yaitu :

a. untuk periode ke-11 (Tahun 2021)

$$
\begin{aligned}
& \mathrm{F}_{10+1}=a_{10}+b_{10}(1) \\
& \mathrm{F}_{10+1}=375.124+21302(1) \\
& \mathrm{F}_{11}=396.516
\end{aligned}
$$

b. untuk periode ke-12 (Tahun 2022)

$$
\begin{aligned}
& \mathrm{F}_{10+2}=a_{10}+b_{10}(2) \\
& \mathrm{F}_{10+2}=375.124+21302(2) \\
& \mathrm{F}_{12}=417.818
\end{aligned}
$$

c. untuk periode ke-13 (Tahun 2023)

$$
\begin{aligned}
& \mathrm{F}_{10+3}=a_{10}+b_{10}(3) \\
& \mathrm{F}_{10+3}=375.124+21302(3) \\
& \mathrm{F}_{13}=439.120
\end{aligned}
$$

Selanjutnya, akan dilakukan plot data berdasarkan nilai peramalan garis kemiskinan di Kabupaten Purbalingga tahun 2011-2023. Hasil plot data dapat dilihat pada Gambar 2. Berdasarkan Gambar 2 menunjukkan nilai peramalan garis kemiskinan di Kabupaten Purbalingga tahun 2011-2023 mengalami kenaikan dari tahun sebelumnya. 


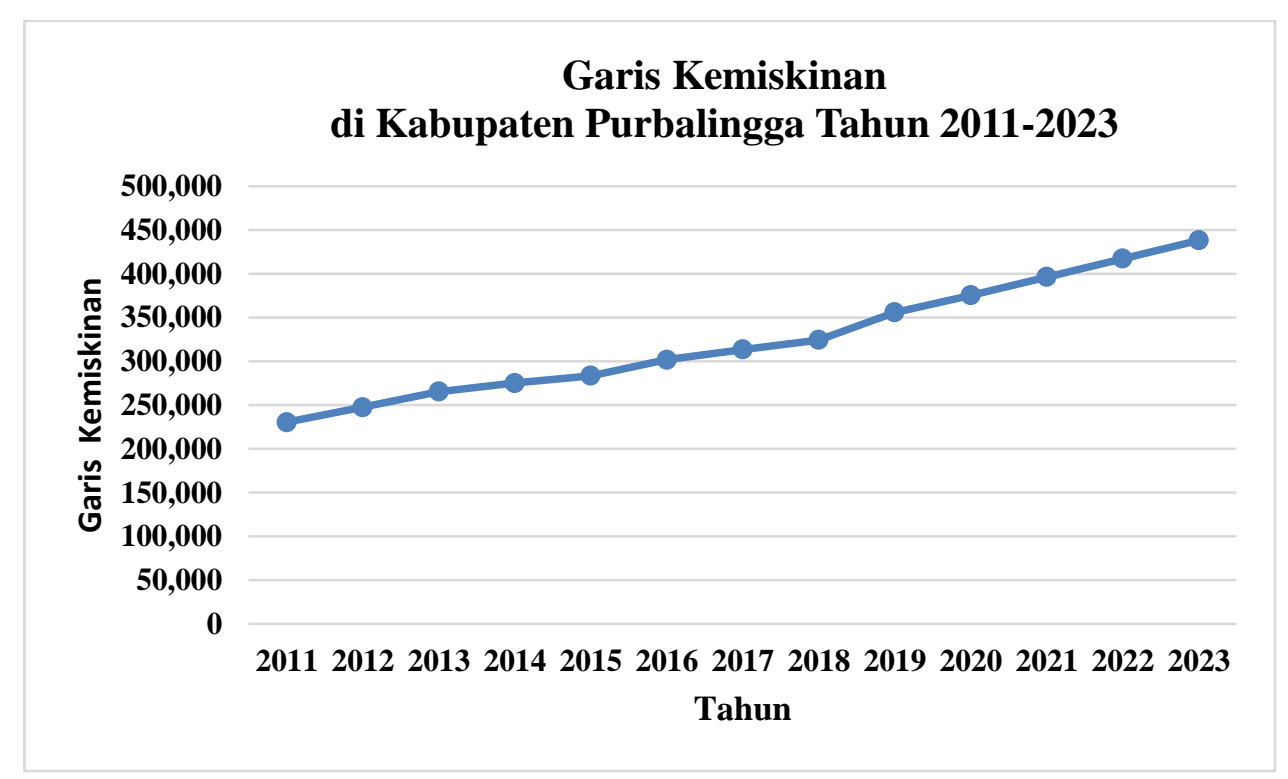

Gambar 2. Plot data peramalan garis kemiskinan di Kabupaten Purbalingga tahun 2011- 2023

Kemudian, akan dihitung nilai MAPE untuk peramalan garis kemiskinan tahun 2011 sampai dengan tahun 2020 secara manual. Langkah-langkah menghitung nilai MAPE adalah menghitung nilai error, presentase error dan mutlak presentase error untuk setiap tahunnya terlebih dahulu. Hasil perhitungannya dapat dilihat pada Tabel 3. Rumus yang digunakan untuk mencari nilai-nilai tersebut yaitu:

1. nilai error

$$
e_{t}=X_{t}-F_{t}
$$

2. nilai persentase error

$$
P E=\frac{|\mathrm{Xt}-\mathrm{Ft}|}{x t} \times 100
$$

3. nilai MAPE

$$
\mathrm{MAPE}=\frac{1}{n} \sum_{t=1}^{n}|P E|
$$

Tabel 3. Hasil perhitungan peramalan garis kemiskinan di Kabupaten Purbalingga tahun 2011-2020 beserta nilai errornya

\begin{tabular}{|r|r|l|l|l|l|}
\hline Tahun & $\begin{array}{c}\text { Garis Kemiskinan } \\
\text { (Rupiah) }\end{array}$ & $\mathbf{F}_{\mathbf{t}+\mathrm{m}}$ & $\mathbf{e}$ & $\mathbf{P E}$ & $|\boldsymbol{P E}|$ \\
\hline 2011 & 230.461 & & & & \\
\hline 2012 & 247.508 & & & & \\
\hline
\end{tabular}




\begin{tabular}{|c|c|c|c|c|c|}
\hline 2013 & 265.262 & 254.327 & 10.935 & 4,122415 & 4,122415 \\
\hline 2014 & 275.022 & 277.989 & -2.967 & 1,078863 & 1,078863 \\
\hline 2015 & 283.366 & 287.546 & -4.180 & 1,475277 & 1,475277 \\
\hline 2016 & 301.862 & 293.951 & 7.911 & 2,620661 & 2,620661 \\
\hline 2017 & 313.343 & 315.235 & -1.892 & 0,603905 & 0,603905 \\
\hline 2018 & 324.375 & 326.671 & -2.296 & 0,707929 & 0,707929 \\
\hline 2019 & 355.702 & 336.615 & 19.087 & 5,366149 & 5,366149 \\
\hline 2020 & 375.199 & 375.370 & -171 & 0,04553 & 0,04553 \\
\hline \multicolumn{3}{|c|}{ Jumlah } & 26.426 & 16,7866 & 16,7866 \\
\hline \multicolumn{5}{|c|}{ MAPE } & $1,67866 \%$ \\
\hline
\end{tabular}

Dilihat dari perhitungan nilai MAPE dengan software Zaitun Time Series dan cara manual diperoleh hasil yang sama yaitu $1,67866 \%$ artinya model peramalan ini memiliki kinerja yang sangat bagus, sehingga model peramalan garis kemiskinan di kabupaten Purbalingga dengan metode double exponential smoothing linier satu parameter dari Brown dapat digunakan untuk jangka panjang.

\section{KESIMPULAN DAN SARAN}

Berdasarkan hasil dan pembahasan, dapat diambil kesimpulan yaitu bentuk persamaan peramalan garis kemiskinan di Kabupaten Purbalingga tahun 2021 sampai dengan tahun 2023 berdasarkan data garis kemiskinan di Kabupaten Purbalingga tahun 2011 sampai dengan tahun 2020 yaitu $F_{t+m}=375.124+21302$ (m). Hasil peramalan garis kemiskinan di Kabupaten Purbalingga tahun 2021 sampai dengan 2023 mengalami kenaikan dari tahun sebelumnya, yaitu pada tahun 2021 (periode ke-11) sebesar Rp 396.516, tahun 2022 (periode ke-12) sebesar Rp 417.818, dan tahun 2023 (periode ke-13) sebesar Rp 439.120. Nilai MAPE yang dihasilkan dalam permalan ini adalah sebesar 1,67866\% dengan nilai parameter optimum yaitu $\alpha=0,7$. Hal ini menununjukkan bahwa peramalan garis kemiskinan di Kabupaten Purbalingga dengan metode double exponential smoothing linier satu parameter dari Brown mempunyai kinerja yang sangat bagus sehingga dapat digunakan dalam jangka panjang. 


\section{DAFTAR PUSTAKA}

Aminudin, R., Handoko, Y., Model Peramalan Garis Kemiskinan Menggunakan Metode Double Exponential Smoothing dari Holt, Jurnal Tata Kelola Dan Kerangka Kerja Teknologi Informasi, 5(1) (2019).

Badan Perencanaan dan Pembangunan Nasional (BAPPENAS), https://www.bappenas.go.id/files/1413/5228/2735/bab-

16_20090202204616_1756_17.pdf, diakses pada 20 Maret 2021.

Fachrurrazi, S., Peramalan Penjualan Obat Menggunakan Metode Single Exponential Smoothing pada Toko Obat Bintang Geurugok, TECHSIJurnal Teknik Informatika, 7(1) (2019), 19-30.

Ferima Talia, I., Fitri Astuti, I., Peramalan Tingkat Kemiskinan Penduduk Provinsi Kalimantan Timur Menggunakan Metode Double Exponential Smoothing, Prosiding Seminar Nasional Ilmu Komputer dan Teknologi Informasi, 4(2) (2019), 121-127.

Goh, C. dan Law, R., Modeling and Forecasting Tourism Demand for Arrivals with Stochastic Nonstationary Seasonality and Intervention, Tourism Management, 23 (2002), 499-510.

Hanke, J. E., Wichern, D. W., Business Forecasting Eight Edition, Pearson Prentice Hall, New Jersey, 2005.

Inayah, Z., Perbandingan Metode Holt dan Brown pada Double Exponential Smoothing (Peramalan Jumlah Kejadian TB Paru), Tesis, Universitas Airlangga, Surabaya, 2010.

Makridakris, S., Wheelwright, S. C., Mc Gee, V. E., Metode dan Aplikasi Peramalan, Jilid I, Erlangga, Jakarta, 1993.

Pemerintah

Kabupaten

Purbalingga,

2019 ,

https://www.purbalinggakab.go.id/v1/angka-kemiskinan-kabupatenpurbalingga-turun-jadi-1503/, diakses pada 20 April 2021.

Wikipedia, Garis kemiskinan, 2008, https://id.wikipedia.org/wiki/Garis_kemiskinan, diakses pada 20 April 2021. 